\title{
Cartaphilus
}

Revista de investigación y crítica estética

\section{LA VERDADERA TRAGEDIA DE LA EXISTENCIA HUMANA SEGÚN LA ESTÉTICA DE THOMAS LIGOTTI}

THE REAL TRAGEDY OF HUMAN EXISTENCE ACCORDING TO THE LIGOTTIAN AESTHETICS

\section{SIMONE MARINO-CICINELLI}

UNIVERSIDAD DE SALAMANCA

Resumen: El presente artículo está dedicado a presentar brevemente la trayectoria bio-bibliográfica de Thomas Ligotti, un autor sumamente reconocido en Estados Unidos, donde se destacarán los principales acontecimientos biográficos y las obras narrativas y filosóficas que más han marcado su trayectoria. Asimismo, se tendrán en cuenta las etiquetas ("metafísico", "filosófico", "pesimista", "nihilista", entre otras) que se le han otorgado a Ligotti para definir su narrativa, cuyo centro de estudio es la desdicha del ser humano. Por tanto, el objetivo es el de encontrar un mínimo común denominador de las categorías antes mencionadas, tomando la filosofía pesimista del muy poco conocido Peter Wessel Zapffe como punto central dentro de la estética ligottiana.

Palabras claves: Zapffe, terror, concien- cia, pesimismo, estética ligottiana.

Abstract: This article is dedicated to presenting the Ligotti's bio-bibliographic trajectory, a highly recognized author in the US, in which the main biographical facts and narrative works that have marked his literary production will be noted. In addition, the labels ("Metaphysical", "Philosophical", "Pessimistic", "Nihilistic", among others) that have been given to Ligotti to define his narrative, whose center of study is the misfortune of the human being, will be studied.Therefore, the objective is to find a common minimum denominator of the aforementioned categories, taking the pessimistic philosophy of Peter Wessel Zapffe as the central point within the Ligottian aesthetic.

Keywords: Zapffe, terror, conscience, pessimism, Ligottian aesthetic. 
El secreto mejor guardado de la literatura de horror contemporánea

WASHINGTON POST

Considerado una de las figuras más relevantes dentro del panorama de la literatura de terror contemporánea y apreciada por sus ficciones cargadas de una angustia irritante, Thomas Ligotti nace en 1953 en Detroit, donde se gradúa en estudios ingleses por la Wayne State University. Tiene una adolescencia muy difícil y turbulenta, ya que a los diecisiete años sufre de ataques de pánico y ansiedad que terminan en una intensa depresión ${ }^{1}$. Esta condición inestable, realmente, se convierte en una oportunidad de reflexión en torno al ser humano, una criatura a la que Ligotti considera tan extraña y terrorífica. La vida de Ligotti está marcada por la obsesión asfixiante que guía su existencia, impregna el estilo de su escritura y se instala en cada uno de los lectores ahogados de emociones escalofriantes y espeluznantes, alarmantes y estremecedoras. Así, Ligotti encuentra sus fortalezas en autores como Howard Philip Lovecraft y Arthur Machen, Edgar Allan Poe y Paul Valéry que representan una verdadera y auténtica ruta de escape de la realidad en la que vive y en la que se siente angustiado.

Se asoma al mundo editorial con su primer cuento, "The Chymist", que fue publicado por la Revista Nyctalops el 16 de marzo de 1981. En el mismo año, se dan a conocer otros dos cuentos: "Allan \& Adelaide: An Arabesque", que aparece en Fantasy Macabre y "Les Fleurs", publicado en un fanzine llamado Dark Horizons. Estos tres primeros cuentos le abren las puertas hacia una extensa narrativa que una parte de la crítica contemporánea considera bajo la etiqueta de "terror filosófico", entre otras.

En 1989 aparece su primera colección de relatos extraños, Songs of a Dead Dreamer, en homenaje a su madre y en recuerdo de su padre. El escritor estadounidense y relevante autor en el panorama de la ciencia ficción Michael Swanwick señala que: "Songs of a Dead Dreamer is full of inexplicable and alarming delights... Put this volume on the shelf right between H. P. Lovecraft and Edgar Allan Poe. Where it belongs" (Swanwick, 2008). Así pues, destacamos el primer relato que compone dicha collección, "The Frolic" (1982), convertido en 2007 en una adaptación cinematográfica de 24 minutos dirigida por Jacob Cooney. En algunas reflexiones, el fundador del grupo musical Current 93, David Tibet, recuerda que se quedó profundamente perturbado por aquella historia y que le parecía que el libro le provocaba rechazo a su lectura. Tibet confiesa que

\footnotetext{
${ }^{1}$ En Supernatural Literature of the World, Scott Connors señala que se aleja de la religión católica con solo diez años y que cae en el consumo de sustancias psicoactivas y alcohol (Connors, 2005: 727).
} 
dejó de leer el libro por unas semanas y que no paró de pensar en un pasaje de "The Frolic" donde: "la banalidad de su miedo, el escuálido y estúpido realismo de ese terror que impregna esas palabras que escribió, [era] mucho más desconcertante para mí que todos los dioses idiotas de Lovecraft y las horribles manifestaciones de las profundidades cósmicas" (Tibet, 2003)².

Su reputación comienza a crecer cuando aparece su segunda colección de cuentos, Grimscribe, His Lives and Works (1991), que se volverá a editar en 2015, junto con la primera, bajo el título Songs of a Dead Dreamer and Grimscribe. En una reciente reseña aparecida en Cuadernos del Hontanar se señala que Grimscribe marca de manera significativa la trayectoria literaria de Ligotti en el sentido de que se empieza a cuestionar la realidad que nos circunda, se exploran los senderos oscuros de la naturaleza para denunciar los engaños y el caos que ella misma oculta a los ojos de la humanidad: "Casi todos los cuentos de esta colección comparten el mismo objetivo: revelar que la realidad es solo una máscara compartida, que detrás de esta solo hay caos. Cuestionar la realidad implica cuestionar también la existencia individual y grupal" (Vanred26, 2016).

Con una gran acogida, se publica otra compilación de relatos extraños y terroríficos, Noctuary (1994), a las que le sucede The Nightmare Factory (1996), traducida al español solo en 2006 y un año después convertida en una antología de cómics por la Fox Atomic Comics. En la introducción a la edición original, la escritora de horror gótico Poppy Z. Brite apunta algunas de las líneas de fuerza del horror, afirmando que las historias encubren monumentales misterios, se hacen portadoras de profundas verdades que se quedan prohibidas a los ojos de los seres humanos. Por tanto, el individuo no solo quiere conocer, asegura Brite, sino también, y sobre todo, experimentar la gran muñeca rusa de los secretos cósmicos. De ahí que lo prohibido se convierta, al mismo tiempo, en fascinación perversa. Parece necesario bajar hacia las profundidades, deambular por la oscuridad de las pesadillas para descubrir, conocer y comprender la naturaleza de la realidad. Sin embrago, este deseo profundo no sella sino la condena perfecta y monstruosa para la humanidad: "la mera posibilidad del conocimiento introduce una monstruosa y perversa tentación que tronca los tranquilos placeres de la existencia mundana por las luces brillantes de la alienación, la perdición y, en algunos casos extraños, la condenación eterna" (Brite, 2006: 8).

Algunos años más tarde, se amplía el corpus literario ligottiano con la publicación de su primera novela, My Work Is Not Yet Done (2002), galardonada con los premios "Bram Stoker Award for Best Long Fiction" e "International Ho-

\footnotetext{
2 Señalamos el pasaje de "The Frolic" al que David Tibet hace referencia, relato que ha sido traducido al español como "El retozo" y que aparece en la colleccion La fábrica de pesadiIlas: "a las cunetas y callejones de negra espuma del paraíso, a la húmeda penumbra sin ventanas de algún sótano galáctico, a los huecos remolinos perlados de mares como cloacas, a las ciudades sin etrellas de la locura y a sus suburbios... mi cervatillo fascinado y yo hemos ido a retozar" (Ligotti, 2006).
} 
rror Guild Award" y Teatro Grottesco (2006), colección de relatos que ha sido traducida ya a varios idiomas como, por ejemplo, al español o al polaco. Nos parece enriquecedor lo que, en la revista Détour. Pensada y hecha a mano, Óscar Brox afirma: "resulta difícil expresar hasta qué punto los relatos de Ligotti, este Teatro Grottesco, mina con determinación el concepto de voluntad, el triunfo de la condición humana, para mostrar su reverso tenebroso; la victoria secreta de la renuncia a vivir" (Brox, 2016) ${ }^{3}$.

Además, su producción contempla otros géneros artísticos: la creación en el año 2002 de Crampton, un disco en versión CD de seis poemas grabados con la voz de Ligotti, In A Foreign Town, In A Foreign Land (1997), álbum musical que incluye cuatro relatos interpretados por el grupo inglés Current 93, y la colección Death Poems, publicada en 2004. Recordamos también otros dos álbumes musicales editados por David Tibet en los que, una vez más, la voz de Thomas Ligotti transporta al lector al mundo ficcional: I Have a Special Plan for This World (2000), This Degenerate Little Town (2001) y The Unholy City (2003).

Como podemos comprobar a lo largo de este breve recorrido, estamos ante un escritor cuyo talento ha superado los límites de las barreras culturales, teniendo en cuenta, por un lado, que su obra completa se compone de más de ciento veinte títulos, muchos de los cuales han sido traducidos al italiano, al español, al francés, al polaco y al alemán; y, por otro, que ha recibido varios premios internacionales entre los que destacan "World Fantasy Award for Best Short Fiction" por el relato "The Last Feast of Harlequin" y "Bram Stoker Award for Best Long Fiction" por "The Red Tower". Este último relato ha adquirido una destacada importancia y popularidad desde que fue publicado en la colección The Nightmare Factory. En este sentido, en Horror Literature Through History: An Encyclopedia of the Stories That Speak to Our Deepest Fears, el profesor de la Universidad de Ottawa y crítico literario del género de horror, Sean Moreland ha señalado con respecto al relato: "its atomosphere of decay is inextricable from its allegorical portrayal of a universe that is [...] hostile to creativity, consciousness, and even existence itself" (Moreland, 2017: 552).

\section{Problemas de definición: Thomas Ligotti y las etiquetas}

En nuestra breve revisión bibliográfica, hemos observado que no hay homogeneidad en lo que atañe a la conceptualización teórica de la obra de Thomas Ligotti. En concreto, hemos encontrado varias etiquetas que se suelen utilizar para calificar su narrativa: "metafísica", "filosófica", "pesimista", "nihilista",

\footnotetext{
${ }^{3}$ Entre las colecciones menos citadas por la crítica, pero no por eso menos dignas de ser tenidas en consideración, se encuentran The agonizing resurrection of Victor Frankenstein \& other gothic tales, publicada por la Silver Salamander Press en 1994, y Sideshow and Other Stories, editada por Subterranean Press en 2003, así como su última publicación The Spectral Link, que aparece en 2014.
} 
"cósmica" y "ontológica".

En primer lugar, cabe destacar que, en una reciente investigación, Sergio Armando Hernández Roura delimita la confusión de algunos de los términos, haciendo un interesante análisis desde el punto de vista de la teoría de lo fantástico. Hernández Roura retoma la dicotomía entre el miedo físico o emocional y el miedo metafísico o intelectual, propuesta por el teórico de lo fantástico David Roas en su estudio "Hacia una teoría sobre el miedo y lo fantástico". Roas aclara tal distinción afirmando que el miedo físico se origina cuando acontecimientos y formas naturales sacuden la seguridad de los lectores de forma física y material, violenta y mortal, como, por ejemplo, invasiones de bichos o catástrofes, vampiros y serial killers. El miedo metafísico, en cambio, si bien está experimentado por los protagonistas de las narracciones, afecta de primera mano al destinatario el cual no reconoce lo que anteriormente para él era familiar y cotidiano. Es decir, el asombro y el miedo que deberían manifestarse en los personajes se trasladan al lector que se covierte en el receptor directo, capaz de problematizar fenómenos y presencias imposibles (Roas, 2011: 95-96). Así pues, Hernández Roura se aleja de la categoría metafísica señalando que: "si el miedo que genera la literatura fantástica es metafísico, el uso de este término no sirve para hacer la distinción de este autor [Ligotti] con respecto al resto de obras de género fantástico, que igualmente producen "miedo metafísico"” (Hernández Roura, 2013: 136137).

Sin embargo, el debate sobre cómo debe ser considerada la obra de Thomas Ligotti se ha extendido ya por varios años enfrentando entre sí a académicos, críticos, periodistas y lectores, sin llegar nunca a un consenso. A este propósito, nos parece conveniente recordar las palabras que Thomas Ligotti concede en una entrevista, realizada por Luca Fusari y publicada en Prisma, ya que nos ofrece una llave de lectura de su filosofía narrativa:

Fantasmas, vampiros, criaturas de otras dimensiones, objetos inanimados que toman vida y cosas por el estilo. Naturalmente, el miedo de estas cosas nos lleva a negar su existencia. No queremos que sean verdaderas porque, de una manera u otra, estas monstruosidades nos revelan que el mundo no es natural (Fusari, 2016).

Ligotti recalca la idea de que el ser humano concibe el mundo de forma natural. Según el estadounidense, en el momento en el que se detectan mecanismos desconocidos y manifestaciones inanimadas se producen sentimientos siniestros ya que experimentamos que el mundo no es como exactamente pensábamos que fuese; es decir, lo concebimos extraño, sobrenatural, no en el sentido religioso o místico sino más bien sospechoso, equívoco, extraño. Es lo que, en La conspiración contra la especie humana, Ligotti subraya como la sensación de "algo erróneo": "incluso las cosas más comunes y corrientes pueden darnos esta impresión. En un abrir y cerrar de ojos pueden dejar de ser vistas de la ma- 
nera en que usualmente las vemos y pasar a ser vistas como algo diferente, algo que quizá no podamos nombrar" (Ligotti, 2017: 110). Al respecto, se quiere destacar que dicha imposibilidad de nombrar está conectada con la definición de espeluznante que Mark Fisher explora en el ensayo Lo raro y lo espeluznante, publicado en 2016. El escritor y crítico británico sostiene que si lo raro es una sensación que surge por una presencia que nos circunda y que no debería estar en aquel momento, lo espeluznante, por el contrario, se manifiesta cuando hay una falta de ausencia o una falta de presencia. Sin embargo, aunque la distinción sea sutil, lo espeluznante oculta siempre en sí mismo un cuestionamiento, una especulación, asegura Fisher; añade un toque de suspense para que el espectador pueda investigar y problematizar (Fisher, 2018: 75-76). Ligotti lo afirma en su ensayo teórico cuando reflexiona sobre la naturaleza y el origen de unos zapatos que están en el suelo del armario, se pregunta el motivo por el cual debería haber algo en vez de nada, trata de razonar sobre el uso del objeto cotidiano que deja de serlo en el momento en el que una voz del mas allá irrumpe en la vida de golpe y transforma todo en un sentimiento siniestro (Ligotti, 2017: 111). El estadounidense lo concreta en el cuento "Dr. Voke and Mr. Veech", que se encuentra en The Shadow At the Bottom of the World, donde aparece el mismo cuestionamiento por parte del Doctor Voke con respecto a los muñecos: "the question is not: 'What is the laughter for,' not at all. The question is: 'Where does it come from?' This is the thing of real horror, in fact. The dummy terrorizes you, while he is really the one in terror" (Ligotti, 2005: 56-57).

Así pues, cabe la pregunta respecto a la manera en la que produce este cambio de mirada y de percepción en el universo escritural de Thomas Ligotti. En una entrevista realizada por chat el 3 de diciembre de 1998, Ligotti afirma:

If I had to describe the general outlook expressed by my horror stories, I suppose that terms like "nihilistic" and "pessimistic" would serve well enough for conventional purposes. Essentially, I just have a very negative attitude about life, the universe and everything. Any given story I write, simply, serves as an occasion to develop this attitude (Ligotti, 1998).

Dicha afirmación nos lleva a centrar la atención en un tipo de escritura donde el horror y lo repugnante están anclados en la actitud de Thomas Ligotti de ver la vida de manera negativa. Sin embargo, no se piense que esta negatividad sea el corazón latiente de la narrativa ligottiana. Esta actitud deriva de la espeluznante toma de conciencia de nuestra naturaleza. Ligotti hace hincapié

\footnotetext{
${ }^{4}$ En "Un recorrido por la obra de este enigmático escritor", Daniel Ortiz recoge las palabras de Thomas Ligotti que demuestran la desaprobación acerca de la etiqueta "nihilista": "es un nombre que otra gente te pone. Ninguna persona inteligente nunca se dice o bien se describe a sí misma como un nihilista" (Ortiz, 2010: 51-52).
} 
una vez más en que el ser humano está vivo y sabe que algún día morirá5. A partir de este esquema, el escritor de Detroit concentra sus argumentaciones en el hecho de que el individuo está afligido por aquel miedo universal que atormenta el alma humana: la muerte. Esta cesanción que afecta al cuerpo humano, sobretodo, en el sentido físico. Podríamos decir incluso que la muerte es metáfora de aquella falta de presencia a la que Fisher aludía en su ensayo teórico. A este respecto, en La conspiración contra la especie humana se hace referencia a la Terror Management Theory postulada por un equipo de profesores de psicología, Sheldon Solomon, Jeff Greenberg y Tom Pyszczynski. Recordamos que la TMT está inspirada en los principios que el antropólogo cultural y pensador estadounidense Ernest Becker formula en La negación de la muerte (1973). Becker sostenía que el ser humano se diferencia de los animales justamente porque puede concibir la muerte a través de un acto reflexivo, ideal y conceptual. Por un lado, los animales que viven sus vidas sin pensar en su autodisolución -y si lo hicieran sería algo pasajero e instantáneo-; por otro, los seres humanos capaces de reflexionar sobre la muerte en sí misma, cuáles son las causas que llevan a la muerte y qué tipos de estrategias se puden emplear para no morir (Becker, 2000: 62).

Ahora bien, Ligotti resume las investigaciones de los profesores antes mencionados afirmando que: "la TMT indica que el resorte principal del comportamiento humano es la tanatofobia, y que ese miedo determina el pasaje entero de nuestras vidas" (Ligotti, 2017: 195). Como se puede comprobar, este dolor cósmico surge de la incapacidad de comprendernos totalmente hasta el fondo. Tiene sus raíces en el hecho de percibir el cuerpo como real, tangible y, al mismo tiempo, ser consciente de que somos individuos que sufren y que mueren. En este sentido, en una entrevista por Matilde Quarti, Ligotti asevera: "es esta toma de conciencia que interpreto como nuestra terrible realidad" (Quarti, 2018).

Así pues, no será descabellado considerar el mundo ficcional del estadounidense conforme a una visión de ver la vida totalmente negativa, una actitud que le sirve para describir lo indescriptible, lo que no se puede decir, lo que no debería estar allí. Ligotti es claro a este respecto: "Usually the views and attitudes are exaggerations, or more accurately, idealizations, of my own views and attitudes at the time I'm writing the story. Over time, I've found that these views and attitudes have remained fairly consistent and fairly negative" (Ligotti, 1998).

Teniendo en cuenta lo anterior, es cierto que muchos de sus relatos son pesimistas y que hay, efectivamente, cuentos que adquieren un perfil metafísico, como, por ejemplo, "The clown puppet", que Jason Marc Harris menciona en su investigación, afirmando que los efectos desconcertantes que provoca el payaso

5 "Para el resto de los organismos terrestres [los animales], la existencia es relativamente simple. Sus vidas giran en torno a tres cosas: sobrevivir, reproducirse, morir... y nada más. Pero nosotros sabemos demasiado para contentarnos con sobrevivir, reproducirnos, morir... y nada más. [...] sabemos que sufrimos durante nuestra vida antes de sufrir -lenta o rápidamente-cuando nos acerquemos a la muerte" (Ligotti, 2017: 38). 
se siguen experimentando en el narrador a pesar de que se está tratando de una simple herramienta o juguete (Harris, 2012: 1255-1256). También estamos de acuerdo con todos aquellos que califican la narrativa de Thomas Ligotti bajo el "terror filosófico" o cuando los editores españoles convienen en que Ligotti es el creador del "terror ontológico" (Palacios, 2016: 17).

Sin embargo, el punto clave es Ligotti intenta sintetizar una profunda preocupación acerca de la condición humana y de su impermanencia en el mundo. Es decir, en lo que se quiere incidir es en la especial reflexión sobre la naturaleza del ser humano. Por un lado, la presencia de un mundo sin mundo, de una realidad irreal llena de horrores ocultos. Por otro, el individuo inmerso en tal oscuridad, invadido de pensamientos alarmantes y horrendos, amenazado por la disolución de su propia carne y por el fluir de las horas. El ser humano es filósofo de sí mismo, en el sentido de que madura un dialogo interior en el que puede escuchar su propia conciencia infernal. Ésta es la verdadera tragedia de la existencia humana, asegura Ligotti, una conciencia que desentierra horrores, revelándole su verídica existencia: "pedazos de carne que se estropea sobre huesos que se desintegran" (Ligotti, 2017: 39). Lo anterior queda reflejado en el relato "Demente velada de expiación", donde el Doctor Francis Haxhausen sostiene:

Lo único que hemos construido es una intricada fachada para ocultar nuestros traumas de inmortalidad, una falsa máscara que esconde los sufrimientos de la raza humana. Ah la raza humana. Y comencé a comprender [...] que tanto el paraíso perdido del pasado como el que buscamos en el futuro eran tan sólo prácticas excusas para nuestro verdadero destino... la desintegración (Ligotti, 2016: 147).

En este punto, la conciencia toma un lugar central dentro del pensamiento ligottiano. Por ello, no podemos dejar de lado, por la importancia que tiene, el pesimismo cósmico del filósofo noruego Peter Wessel Zapffe para entender profundamente a nuestro autor. No hemos de olvidar que Ligotti le rinde homenaje en su único ensayo teórico cuyo éxito inicial tiene un efecto ejemplar: The Conspiracy against the Human Race (2010), publicado, por primera vez, en España en 2015 por la Editorial Valdemar y, un año después, en Italia por la Editorial II Saggiatore.

\section{Zapffe y las cuatro estrategias}

A pesar de que la labor narrativa de Thomas Ligotti se caracterice por las etiquetas a las que hemos hecho alusión en el apartado anterior, podemos constatar que La conspiración contra la especie humana tiene unos fundamentos teóricos pesimistas bastante claros. Es decir, está anclada en lo que, en "El último Mesías", Peter Wessel Zapffe ha definido como el relentless panic (Zapffe, 2016). La mente humana vive en un estado de pánico implacable y cósmico debido a la 
existencia de una conciencia que, según Zapffe, revela al ser humano lo terrorífico y lo repugnante que es estar vivo. Lo primero que hay que tener en consideración es que la filosofía de Zapffe encuentra su origen en autores como Friedrich Nietzsche, Arthur Schopenhauer o Sigmund Freud, cuyos pensamientos se alejan totalmente de una existencia sobrenatural o divina para centrar la atención en la condición humana. Si tomamos el caso de Schopenhauer, queda claro que la vida es uno de los problemas al que se enfrenta el ser humano, quien, a lo largo de su existencia, experimenta profundos dolores. Así pues, conforme a la reflexión schopenhaueriana puede que la humanidad llegue a un punto en el que considere la muerte como solucción y acción benéfica para poner fin a todo sufrimiento. En este sentido, en "Sobre el suicidio", se afirma: "pero hay en este final algo positivo: la destrucción del cuerpo. Esto es lo que da miedo, precisamente porque el cuerpo es la manifestación de la voluntad de vivir" (Schopenhauer, 1998: 149-150). Si a esto añadimos que se pueden padecer sufrimientos espirituales mucho más elevados que aquellos físicos, no resulta extraño comprender, sostiene el filósofo alemán, que el acto autodestructivo se convierta en una acción benéfica, un alivio, una distracción para dar fin a todo sufrimiento.

De forma semejante, en las actas de la sociedad psicoanalítica de Viena recopiladas por Nunberg y Federn, Sigmund Freud intenta explicar, en términos psicoanalíticos, que en el ser humano hay un potencial suicida que le acompaña desde el nacimiento hasta sus últimos días y que la propia destrucción está causada por una serie de acontecimientos y conflictos interiores: "no se debe olvidar que el suicidio no es sino una salida, una acción, un desenlace de conflictos psíquicos, y lo que corresponde explicar es el carácter del acto y de qué modo el suicida pone fin a la resistencia contra el acto suicida" (Nunberg; Federn, 1979: 50).

El noruego Zapffe no se distancia mucho de estas posturas y madura la idea de que la existencia humana no es sino una paradoja biológica, un extraño ser aberrante que ha sido catapultado en el mundo. Una especie absurda cuyo sufrimiento "horada agujeros que le conducen a un miedo hacia el mundo y a una desesperanza vital" (Zapffe, 2016). Es una criatura que percibe su propia locura, desea enfrentarse a la oscuridad, a la muerte inminente. Sin embargo, este momento lleva en sí una toma de conciencia por parte del individuo de su naturaleza; comprende que no existe ninguna redención ni salvación más allá de la muerte. De ahí que se produzca esa sensación de pánico cósmico, un estado perenne en la mente humana. Por otra parte, sostiene Zapffe, la desgracia de la raza es la de haber sobrepasado el límite de su evolución; es decir, haber superdesarrollado una mente, una capacidad máxima de pensamiento e intelecto hasta el punto de resultar inadecuada y de ser ella misma la causa de la disolución de la especie humana (Zapffe, 2016). De este modo, el antinatalista plantea cuatro tipos de estrategias para reprimir nuestra conciencia: aislamiento, anclaje, distracción y sublimación, que posteriormente, Thomas Ligotti ejemplifica en su ensayo teórico: 
1. Aislamiento: mecanismo que permite ocultar hechos terribles de la vida en un cajón de nuestro cerebro para así no caer en el tormento, en la angustia y en la depresión.

2. Anclaje: creencia en verdades metafísicas e institucionales como Dios, Moral, Ley Natural, País, Familia que representan seguridades auténticas y oficiales pero, al mismo tiempo, efímeras. Creemos en un Dios salvador que aplaca toda culpa humana y nos tranquiliza. De igual manera, nos sentimos cómodos y protegidos en los hogares familiares; el conocimiento de lo qué es bien o mal nos trasmite una sensación de firmeza. Así, Zapffe ha expresado ese carácter salvífico:

Amamos los anclajes porque nos dan la salvación, pero a la vez los despreciamos porque cercenan nuestro sentido de la libertad [our sense of freedom]. Cuando nos sentimos lo suficientemente fuertes, nos causa placer ir de la mano a sepultar [bury] algún caduco valor [puesto] de moda. Los objetos materiales adquieren entonces un significado simbólico (enfoque [aproximación] Radical a la vida) (Zapffe, 2016).

3. Distracción: inmersión en un mundo de basura insignificante y superfluo como televisores o redes sociales que no hacen sino convertirnos en seres pasivos donde ya no es posible el contacto cara a cara, sino "pantalla a pantalla".

4. Sublimación: estrategia empleada por los pensadores y los artistas, los escritores de ficciones y de historias sobrenaturales que subliman los temores exponiéndolos abiertamente. En este contexto, Ligotti señala que se "confeccionan productos que permiten escapar de nuestro sufrimiento mediante una simulación ficticia del mismo - por ejemplo, un drama trágico o una elucubración filosófica" (Ligotti, 2017: 42).

Estos rasgos que vienen presentándose confirman que la conciencia siempre ataca de frente, sin ninguna piedad, nuestra estabilidad. En el célebre artículo "Thinking horror" publicado en Collapse en 2008, Thomas Ligotti resume las argumentaciones expuestas por Zapffe, afirmando que la desgracia, para el ser humano, empezó cuando logró alcanzar la conciencia, un producto accidental de nuestra evolución, un imprevisto que convertí la especie humana en una raza de monstruos (Ligotti, 2008: 216). Por esto, Thomas Ligotti se refiere a la conciencia como fuente absoluta de los horrores a los que están sometidos los miembros de nuestra especie. Una tragedia total que, no por casualidad, el noruego Zapffe ha visto claramente como la "hermandad de sufrimiento entre todo lo que está vivo" (Ligotti, 2017: 37). El ser humano necesita seguridad, mecanismos de defensa, pretende minimizar todo pensamiento macabro. Intenta fortalecer, explica Ligotti, la idea de que una marioneta no puede cobrar vida simple- 
mente por ser un juguete y, aún así, sus ojos nos alarman (2017: 23). Por lo tanto, se hace evidente el hecho de que, vayamos donde vayamos, no hay escapatoria. La conciencia, así como los pensamientos que amenazan el alma, nos pueden angustiar en cualquier momento. En realidad, pues, dirá Ligotti: "nos convertimos susceptibles a pensamientos que eran alarmantes y espantosos para nosotros. Pienso, luego existo y algún día moriré" (Ligotti, 2008: 216). Es más, casi al final de su artículo, Ligotti lo concreta del modo siguiente: "podemos tolerar la existencia solo si creemos [...] que no somos lo que somos: irrealidad sobre las piernas" (228).

En este sentido, en Dark Matter: British Weird Fiction and the Substance of Horror, 1880-1927, Anthony Christopher Camara, parafraseando, concluye que las ficciones de Thomas Ligotti se caracterizan por la ausencia de una realidad subyacente a la materia y al mundo exterior y que los personajes de sus historias están "sumidos en la irrealidad de sus propios espacios psicológicos" (Camara, 2013: 69). Queremos añadir que es en esta irrealidad en la que el ser humano experimenta la gama completa de los horrores que están arraigados dentro de él, sensaciones hermanas al miedo y emociones terroríficas, pensamientos e inquietudes angustiantes, donde quizá lo único que le queda sea refugiarse en los sueños. En realidad, asume que no son sino su propia condena: se desploma "finalmente en la cama a sudar en el pozo negro del sueño profundo o hervir a fuego lento en las fantasmagorías que importunan nuestras mentes cuando sueñan" (Ligotti, 2017: 278). De ahí, la pregunta de para qué vivir si somos seres autolimitados, paradójicos y que nos deshacemos; tal vez, asegura el filósofo Zapffe, deberíamos dejar de reproducirnos.

Esta concepción zapffeana se recoge en el ensayo teórico de Ligotti, el cual retoma varias aportaciones de filósofos (Arthur Schopenhauer, Philipp Mainländer, David Benater, William James) para reforzar la idea anti-naturalista por la que el ser humano debería extinguirse de forma pacífica. Para ilustrar mejor la idea, Ligotti pone el ejemplo, Mejor no haber sido nunca: el daño de venir a la existencia, del filósofo y académico de la University of Cape Town David Benater, según el cual el nacimiento es ausencia de felicidad y el sufrimiento deriva justamente de la venida a este mundo. Por lo tanto, entre aquellos que sufren porque han nacido y los que no sufren porque no lo hicieron, resume Ligotti, la mejor opción es aquella de no tener hijos (Ligotti, 2017: 83).

De forma semejante, en "Sobre la teoría del dolor del mundo", Schopenhauer señala que el grado de felicidad del género humano se mide no tanto por la frecuencia de placeres y alegrías sino por la inmensa ausencia de sufrimientos. Así pues, el filósofo alemán ofrece una distinción entre los animales y los seres humanos, afirmando que si en los primeros los acontecimientos dolorosos se perciben como si fuera siempre la primera vez, debido a la falta de reflexión y de pensamiento, en los segundos, en cambio, se van sumando; es decir, se produce una "intensificación del sentimiento de la propia felicidad e infelicidad, que puede conducir o hasta un momentáneo, y a veces incluso mortal, espasmo de gozo, 
o al suicidio desesperado" (Schopenhauer, 1998: 123-124).

Por lo tanto, no se equivoca cuando, en Weird mysticism: philosophical horror and the logic of negation in Thomas Ligotti, Georges Bataille, and E. M. Cioran, el profesor y teórico de la Pennsylvania State University Brad Baumgartner argumenta que Ligotti edifica una literatura que se caracteriza por conceptos filosóficos como la autoaniquilación, la disolución, el vacío, la obscuridad, entrelazados por tramas sobrenaturales, lenguajes místicos y personajes extraños: estrategias escriturales que permiten el acceso a áreas del pensamiento nunca antes exploradas (Baumgartner, 2015: 31). Por lo anterior, a medida que se van leyendo sus obras terminamos por ser atrapados en la cósmica tela ligottiana: un universo donde el lector se adentra en los senderos obscuros de la ficción de terror y de lo extraño, donde todo puede ocurrir. Una mano nos sacude bruscamente; en realidad, no sabemos si es aquella de un monstruo lovecraftiano del más allá o la de una marioneta que con su mirada nos petrificaría abruptamente. No sabemos si aquella entidad que acontece en el espacio oscuro existe. Sin embargo, en la literatura ligottiana la incerteza de que algo exista se convierte en la única certeza que pueda existir verdaderamente porque no hay ninguna explicación que niegue la existencia. A este respecto, en el relato "La Medusa", el protagonista Lucian Dregler lo confirma:

No existe nada en la naturaleza de las cosas que haga totalmente imposible que un hombre vea un dragón o un grifo, una Gorgona o un unicornio. Nadie, de hecho, ha visto jamás a una mujer cuyo cabello esté compuesto de serpientes, ni a un caballo de cuya frente se proyecta un cuerno [...]; los monstruos de la heráldica y la mitología no existen, pero no existe ninguna razón en la naturaleza de las cosas ni en las leyes de la mente por las que no podrían existir (Ligotti, 2016: 41).

De este modo, se experimentan los miedos que atormentan y que obcecan, por un instante, el entendimiento. Lo dicho queda implícito en las palabras de Jesús Palacios que advierte que Thomas Ligotti funda una literatura que sale de los cánones típicos de la narrativa de terror contemporánea, para crear "un universo propio donde no existen leyes narrativas fijas ni explicaciones tranquilizadoras" (Palacios, 2016: 15-16).

Es curioso observar que dichos conceptos filosóficos que acabamos de mencionar parecen haber vuelto en la literatura de finales del siglo XX y comienzo del siglo XXI. Asimismo, el pensamiento pesimista y las teorías antinatalistas parecen haber encontrado su sitio en un género literario, cuyas fronteras escriturales se expanden hacia lo impensable, lo incompleto y lo invivible, entre muchos otros. Nos referimos al género del horror y de lo extraño que festeja la desdicha de la raza humana acogiendo la filosofía de Nietzsche y Schopenhauer, Zapffe y Cioran, Sully y Mainländer. Según este último, el más alto conocimiento al que la humanidad debe aspirar, de forma conciente, es que la vida es ausencia de sen- 
tido, es sólo una caja de dolores y de sufrimientos cósmicos, de impulsos negativos que angustian al alma. De ahí, de acuerdo con Ligotti, que sea necesario refugiarse en el mismo corazón del horror, volver a la nada, recuperar aquella felicidad genuina que solo la muerte y la disolución del cuerpo te puede ofrecer.

En este sentido, en "Pesimismo cósmico", Eugene Thacker asienta que los seres humanos están condenados a la inutilidad y al fracaso, a la derrota y al descontento, un melodrama, por cierto, cuyo título recuerda al de La conspiración contra la especie humana de Thomas Ligotti. Así pues, es cierto que ninguno quiere ser pesimista. Sin embargo, estamos de acuerdo con Thacker cuando argumenta con respecto al pesimismo: "todo el mundo [...] ha de confrontarse con él en algún momento de su vida, si no como filosofía al menos sí como lamento contra uno mismo o los demás, contra lo que le rodea a uno mismo o a la propia vida, contra el estado de cosas o el mundo en general-" (Thacker, 2017).

De forma semejante, en Lo raro y lo espeluznante, Mark Fisher trata de explicar cómo la literatura de lo extraño y del terror favorece, en sus simulacros, la presencia de elementos filosóficos. Por citar algunos de los ejemplos a los que hace referencia Fisher señalemos Picnic en Hanging Rock (1967) de Joan Lindsoy, novela de desapariciones misteriosas de niñas donde la sensación de lo espeluznante está causada por la ausencia y la desaparición. También es el caso de EI glamour (1984) de Christopher Priest, novela en la que se puede apreciar el vacío a través de la amnesia: "un claro caso de nada donde debería haber algo" (Fisher, 2018: 91). Del mismo modo, Fisher abarca la cinematografía de la ciencia ficción contemporánea que cuestiona si el mundo en el que vivimos puede ser un simulacro: Matrix, cuyos efectos especiales contribuyeron a la creación de un mundo fabricado a la perfección.

No nos equivocaríamos si consideráramos en esta órbita la serie de televisión True detective que gira en torno a la filosofía pesimista ${ }^{6}$. La búsqueda del sentido de la vida, la conciencia humana, así como la muerte, son unos de los temas centrales que se han explorado a lo largo de las tres temporadas y que, en el fondo, tienen mayor influencia sobre el ser humano. Al respecto, en un artículo periodístico de Eduardo Fernández, el profesor de filosofía de la Universidad Andrés Bello de Santiago de Chile, Iván de los Ríos reivindica: "el Rust de Pizzolatto es un llorón en términos metafísicos. Un lamento agudo y armado hasta los dientes. Y si uno llora y se lamenta porque nada tiene sentido, entonces, subrepticiamente, está idealizando y anhelando una razón última y un significado trascendental" (Fernández, 2015).

${ }^{6}$ Thomas Ligotti ha sido fuente de inspiración para la serie de televisión True Detective (2014) en la que se incorporaron elementos que formaban parte de la narrativa filosófica ligottiana. Hasta el punto de que el fundador de la página web oficial Thomas Ligotti Online, Jon Padgett acusó de plagio a Nic Pizzolatto, guionista y director de la primera temporada, por haber reflejado, de manera tan explícita, algunos asuntos contenidos en La conspiración contra la especie humana. 


\section{Conclusiones}

Hemos podido constatar a lo largo de esta investigación que Ligotti se hace el precursor de conceptos pesimistas e nihilistas que toman sus fundamentos en la filosofía del noruego Peter Wessel Zapffe, entre muchos otros. En una entrevista por La Stampa, Thomas Ligotti afirma: "La única certeza que tenemos en la vida es que encontraremos el dolor, nosotros y aquellos que amamos. No hay manera de evitarlo" (Silipo, 2016). En este sentido, se ejemplifica la constante e indiscutible preocupación de Thomas Ligotti por que cada individuo tome conciencia de su condición y de su naturaleza: una inquietud que impregna toda su obra literaria. Puede que sea ahí, en la conciencia, donde radique la indudable tragedia de la existencia humana.

\section{BIBLIOGRAFÍA}

BAUMGARTNER, Brad (2015). Weird mysticism: philosophical horror and the logic of negation in Thomas Ligotti, Georges Bataille, and E. M. Cioran. Ann Arbor: Indiana University of Pennsylvania.

BECKER, Ernest (2000). La negación de la muerte. Barcelona: Editorial Kairós.

CAMARA, Anthony Christopher (2013). Dark Matter: British Weird Fiction and the Substance of Horror, 1880-1927. Los Angeles: University of California.

CONNORS, Scott, (2005). Thomas Ligotti. En JOSHI, S. T. - DZIEMIANOWICZ, S. (ed.). Supernatural Literature of the World: An Encyclopedia. Westport: Greenwood, p. 727.

DIACONú, Alina (1998). Preguntas con respuestas. Buenos Aires: Editorial Vinciguerra, p. 41.

FERNÁNDEZ, Eduardo (2015). Schopenhauer en el televisor. El Mundo, 11 de enero, Recuperado en línea: https://www.elmundo.es/television/2015/01/11/54aed0a0268e3e7c308 b456e.html.

FISHER, Mark (2018). Lo raro y lo espeluznante. Barcelona: Alpha Decay.

FUSARI, Luca (2016). Intervista a Thomas Ligotti. Prismo. Recuperado en línea: http://www.prismomag.com/intervista-thomas-ligotti/.

HARRIS, Marc Jason (2012). Smiles of Oblivion: Demonic Clowns and Doomed Puppets as Fantastic Figures of Absurdity, Chaos, and Misanthropy in the Writings of Thomas Ligotti. Journal of Popular Culture, Vol. 45, № 6, pp. 1249-65.

HERNÁNDEZ ROURA, Sergio (2013). Thomas Ligotti: Los delirios de una mente 
rota. Brumal, Vol. 1, № 1, pp.136-137.

LIGOTTI, Thomas (1998). Transcript of Chat with Thomas Ligotti. Event Horizon, diciembre.

------- (2005), The Shadow at the Bottom of the World. New York: Cold Spring Press.

----- (2008). Teatro Grottesco. London: Virgin Books.

----- (2008). “Thinking horror". En Collapse, № 4, pp. 209-258.

-------- (2015). Songs of a Dead Dreamer and Grimscribe. New York: Penguin.

(2016). Noctuario, Relatos extraños y terroríficos, Prólogo de Jesús Palacios. Trad. de Marta Lila. Madrid: Valdemar.

- (2017). La conspiración contra la especie humana, Trad. de Juan Antonio Santos. Madrid: Valdemar.

MORELAND, Sean (2017) The Red Tower: The Universe as a Nightmare Factory. En CARDIN, Matt (Ed.). Horror Literature through History: An Encyclopedia of the Stories That Speak to Our Deepest Fears. California: Greenwood, Vol 2, p. 552.

NUNBERG, Hermann - FEDERN, Ernst (1979). Las reuniones de los miércoles: actas de la Sociedad Psicoanalítica de Viena, 1906-1908. Buenos Aires: Nueva Visión.

ORTIZ, Daniel (2010). Un recorrido por la obra de este enigmático escritor. Insomnia. El universo de Stephen King, № 154, pp. 51-52.

PALACIOS, Jesús (2016). Pasos en la oscuridad. LIGOTTI, Thomas. Noctuario. Relatos extraños y terroríficos. Madrid: Valdemar.

QUARTI, Matilde (2018). Thomas Ligotti, maestro della weird fiction e dell'horror filosofico, si racconta. II Libraio. Recuperado en línea: https://www.illibraio.it/thomas-ligotti-intervista-737991/.

ROAS, David (2011). Tras los límites de lo real. Una definición de lo fantástico. Madrid: Páginas de Espuma.

SCHOPENHAUER, Arthur (1998). Sobre el suicidio. SÁNCHEZ MECA, Diego (ed.). EI dolor del mundo y el consuelo de la religión. Madrid: Alderabán Ediciones, pp. 149-150.

(1998). Sobre la teoría del dolor del mundo. SÁNCHEZ MECA, Diego (ed.). El dolor del mundo y el consuelo de la religión. Madrid: Alderabán Ediciones, pp. 123-124.

SILIPO, Raffaella (2016). "Thomas Ligotti. Con Poe l'incubo è un capolavoro. La Stampa, 13 de febrero. [Fecha de consulta: 4 de enero de 2019].

THACKER, Eugene (2017). Pesimismo cósmico. El vuelo de la lechuza. Traducción 
de Miguel Ángel Mozún Campano, 26 de julio. Recuperado de: https://elvuelodelalechuza.com/2017/07/26/pesimismo-cosmico-deeugene-thacker/.

TIBET, David (2003). Soft Black Star: Some Thoughts on Knowing Thomas Ligotti. DARRELL, Schweitzer (ed.). The Thomas Ligotti Reader: Essays and Explorations. Holicong: Wildside.

WINTER, E. Douglas (1992). Cream de la Scream. The Washington Post, 16 de febrero. Recuperado de: https://www.washingtonpost.com/archive/entertainment/books/1992/0 2/16/cream-de-la-scream/23d6b521-5fef-4d89-8e71a1882dec5240/?utm term $=.386 f 77 c 415 f 5$.

ZAPFFE WESSEL, Peter (2016). El último Mesías. El vuelo de la lechuza. Trad. de Carlos Javier González Serrano. 8 de noviembre. Recuperado de: https://elvuelodelalechuza.com/2016/11/08/el-ultimo-mesias-the-lastmessiah-el-desconocido-pesimismo-de-peter-wessel-zapffe/.

SWANWICK Michael (2008). Praise for Thomas Ligotti. En LIGOTTI, Thomas. Teatro Grottesco. Londres: Virgin Books. 